\title{
Outcome of major spinal deformity surgery in high-risk patients: comparison between two departments
}

Authors Girts Murans ${ }^{1}$, Bengt Gustavsson², Helena Saraste ${ }^{1,3}$ Institution ${ }^{1}$ Institution for Molecular Medicine and Surgery, Karolinska Institute, Stockholm, Sweden ${ }^{2}$ Department of Neurosurgery, Karolinska University Hospital, Stockholm, Sweden

${ }^{3}$ Department of Orthopaedic Surgery, Larolinska University Hospital, Stockholm, Sweden

\begin{tabular}{|c|c|}
\hline $\begin{array}{l}\text { Final class of } \\
\text { evidence-treatment }\end{array}$ & Yes \\
\hline \multicolumn{2}{|l|}{ Study design: } \\
\hline \multicolumn{2}{|l|}{ RCT } \\
\hline Cohort & - \\
\hline \multicolumn{2}{|l|}{ Case control } \\
\hline \multicolumn{2}{|l|}{ Case series } \\
\hline \multicolumn{2}{|l|}{ Methods } \\
\hline \multicolumn{2}{|l|}{ Concealed allocation (RCT) } \\
\hline \multicolumn{2}{|l|}{ Intention to treat (RCT) } \\
\hline \multicolumn{2}{|l|}{$\begin{array}{l}\text { Blinded/independent } \\
\text { evaluation of primary outcome }\end{array}$} \\
\hline Follow-up $\geq 85 \%$ & $\cdot$ \\
\hline Adequate sample size & $\cdot$ \\
\hline \multicolumn{2}{|l|}{ Control for confounding } \\
\hline Overall class of evidence & III \\
\hline \multicolumn{2}{|c|}{$\begin{array}{l}\text { The definiton of the different } \\
\text { classes of evidence is available on } \\
\text { page } 54 .\end{array}$} \\
\hline
\end{tabular}

\section{ABSTRACT}

Study design: Retrospective cohort study

Objective: To describe the outcome and resource use in major spine surgery on high-risk patients, and analyze possible differences between two surgical departments.

Methods: Data from the deformity register and medical records of 136 patients, median age 12-years, with neuromuscular and congenital spinal deformities with and without intraspinal pathology, surgically treated by one surgeon from 1997 through 2004 at two departments. H1 with a pediatric multidisciplinary team, and $\mathrm{H} 2$ with focus on adult spine. Variables at baseline: age, gender, diagnosis, curve size, and type of surgical procedure. Result variables included clinical and radiographic outcome, surgery time, length of intensive care and hospital stay, relative blood loss, and occurrence of complications during 2 or more years follow-up.

Results: There was no perioperative or postoperative mortality, no spinalcord damage, no neurological or ambulatory function deterioration. The overall complication rate was $36 \%$, and the overall major complication rate was $15.4 \%$. The mean loss of correction was $2^{\circ}$ during the follow-up. There were statistically significant differences between the $\mathrm{Hl}$ and $\mathrm{H} 2$ departments. At $\mathrm{Hl}$, deformity correction was better and surgery time shorter. Infections were more frequent at H2 $(P=.04 ; 6 / 65$ at $\mathrm{H} 1 ; 16 / 71$ at H2), tendency $(P=.06)$ of more department-related complications was higher at $\mathrm{H} 2$.

Conclusions: Major spine surgery in high-risk patients can be performed safely and with good outcoms. Impact of organization and workplace culture on the outcome might be important and worth further study.

This project was suppordet by Norrbacka-Eugenia Foundation and Guldbröllupsfonden, Stockholm, Sweden 


\section{STUDY RATIONALE AND CONTEXT}

Early onset, nonidiopathic spine deformities are progressive, associated with increased morbidity and mortality as well as neurological and functional deterioration [1]. With surgical treatment, high complication rates are reported [2-7]. Risk-benefit studies on prospectivly captured data are few [8], and discussions on the need for highly specialized treatment units are not conclusive.

\section{OBJECTIVE}

The objective of this study is to compare outcome, resource use, and complications in pediatric high-risk, spinal deformity surgery between two departments: $\mathrm{Hl}$ with a pediatric multidisciplinary team and $\mathrm{H} 2$ with focus on adult spine.

\section{METHODS}

Study design: Retrospective cohort study.

\section{Inclusion criteria:}

- Surgically treated patients with congenital and neuromuscular progressive spine deformities

- Procedures included segmental fixation (anterior and/or posterior) and fusion with an additional neurosurgery in the same session if indicated

\section{Exclusion criteria}

- Patients with idiopathic spine deformities

- Other than fusion techniques, for instance, Vertical expandable Prosthetic Titanium rib (VEPTR) and growing rod

\section{Patient population and interventions compared (Fig 1)}

- Prospectively captured data from deformity registry and medical records before and after surgery and at 2 or more years follow-up on 136 consecutive, surgically treated patient by one surgeon in two departments: Hl with paediatric multidisciplinary team (1997-2004), and H2 with focus on adult spine (2000-2004).

- The patient assignment to departments was not made by surgeon choice but was administratively conducted.

- The deformity surgery included either a posterior or a combined anterior and posterior procedure with an additional neurosurgery in the same session, if indicated.

- Autogenous bone, occasionally combined with homogenous and/or synthetic bone substitute, was used.

- Neurosurgical procedures included untethering, excision/resection of expansive processes, malformations, and reconstructions in diastematomyelia.

- The patients were optimized regarding nutrition, cardiovascular, and respiratory function. Perioperative prophylactic antibiotics were given. 


\section{Outcomes}

- Clinical and neurological status and functional ambulation, radiographically measured deformity angles, and spine balance before and after surgery and at follow-up were recorded in the deformity registry at the time of each examination by the surgeon. The follow-up recordings and counterchecking of medical reports was conducted by the first author, who did not treat the patients.

- Surgery time, intensive care unit (ICU) stay, and hospitalization time.
- Perioperative relative blood loss.

- Occurence of complications or adverse events.

- See the web appendix for additional details at www.aospine.org/ebsj.

\section{Analysis}

- Statistical significance of comparison between Hl and $\mathrm{H} 2$ regarding outcome variables were calculated using multiple logistic regression to adjust for the baseline differences (see the web appendix for additional details).

\section{H1 (1997-2004)}

$(n=64)$

- Proactive multidisciplinary team

- Individually tailored approach according to diagnosis

- Patients were seen perioperatively by relevant experts, eg, neurosurgeon, neuroradiologist, pulmonologist, urologist, specially trained nurses and paramedical personnel

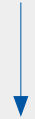

Unavailable for follow-up $(n=0)$

Analyzed $(n=64)$

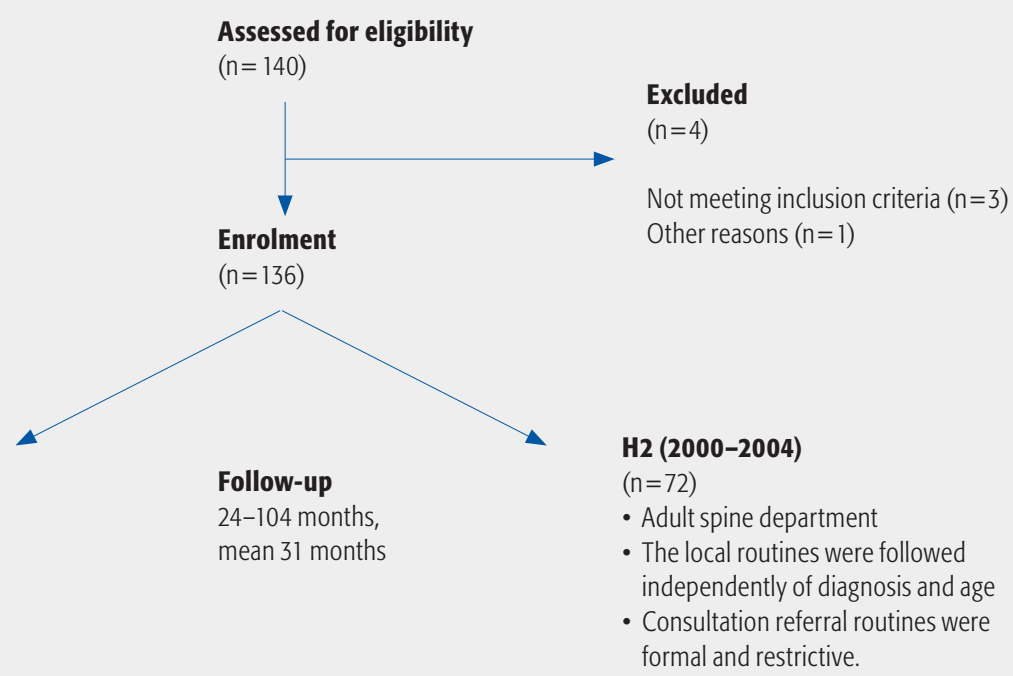

Follow-up

Retrospective analysis Unavailable for follow-up $(n=0)$

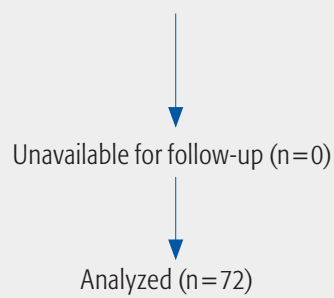




\section{RESULTS}

- The baseline data were comparable between the departments. Hl patients were more likely to be female, wheelchair bound, with diagnosis of spina bifida, and required more neurosurgical intervention (Table 1).

- There was no perioperative nor postoperative mortality. There was no spinal-cord damage nor early or late neurological deterioration. The ambulatory function did not deteriorate in any case (Table 4).

- The overall complication rate was $36 \%$, and the overall major complication rate was $15.4 \%$ (Table 4).

- The mean loss of correction was $2^{\circ}$ during the follow-up (Table 2).

- There were statistically significant differences between the Hland $\mathrm{H} 2$ departments:

- mean deformity correction percentage was higher at $\mathrm{Hl}$ (Table 2),

- surgery time was shorter at $\mathrm{Hl}$ (Table 3),

- infections were more frequent at H2 $(P=.04 ; 6 / 65$ at $\mathrm{Hl} ; 16 / 71$ at $\mathrm{H} 2$ ) (Table 4),

- there was a tendency $(P=.06)$ for more department-related complications at $\mathrm{H} 2$.

Table 1 Demographic and baseline characteristics of groups

\begin{tabular}{|c|c|c|c|}
\hline & $\begin{array}{l}\text { Total study group } \\
n=136\end{array}$ & $\begin{array}{l}H 1 \\
n=64\end{array}$ & $\begin{array}{l}H 2 \\
n=72\end{array}$ \\
\hline Age in years & $12.1 \pm 5.5$ & $11.5 \pm 6.8$ & $12.7 \pm 4$ \\
\hline Female, n (\%) & $68(50)$ & $27(42.2)$ & $41(56.9)$ \\
\hline Number of fused segments & $12.9 \pm 3.6$ & $12.9 \pm 4.2$ & $12.9 \pm 2.9$ \\
\hline \multicolumn{4}{|l|}{ Functional status, $\mathbf{n}(\%)$ : } \\
\hline Full ambulators & $20(14.7)$ & $10(15.6)$ & $10(13.9)$ \\
\hline Ambulators with neurological disease & $10(7.4)$ & $4(6.3)$ & $6(8.3)$ \\
\hline Ambulator with crutches and/or orthotics & $20(14.7)$ & $6(9.4)$ & $14(19.4)$ \\
\hline Wheelchair bound & $86(63.2)$ & $44(68.8)$ & $42(58.3)$ \\
\hline Curve size (Cobb) & $59.14 \pm 29.1$ & $59.8^{\circ} \pm 32.2$ & $58.5^{\circ} \pm 26.1$ \\
\hline \multicolumn{4}{|l|}{ Diagnosis, n (\%): } \\
\hline MMC & $29(21.3)$ & $17(26.6)$ & $12(16.7)$ \\
\hline $\mathrm{CP}$ & $29(21.3)$ & $15(23.4)$ & $14(19.4)$ \\
\hline Duchenne & $6(4.4)$ & $1(1.6)$ & $5(6.9)$ \\
\hline SMA & $12(8.8)$ & $5(7.8)$ & $7(9.7)$ \\
\hline Neuroendocrine & $12(8.8)$ & $6(9.4)$ & $6(8.3)$ \\
\hline Tumor related & $29(21.3)$ & $11(17.2)$ & $18(25.0)$ \\
\hline Congenital & $19(14)$ & $9(14.1)$ & $10(13.9)$ \\
\hline Anterior procedures, n (\%) & $89(65.4)$ & $44(68.8)$ & $45(62.5)$ \\
\hline Neurosurgical intervention, $\mathrm{n}(\%)$ & $34(25)$ & $19(29.7)$ & $15(20.8)$ \\
\hline
\end{tabular}

$\mathrm{MMC}=$ meningomyelocel

$\mathrm{CP}=$ cerebral palsy

SMA = spinal muscular atrophy

Neuroendocrine $=$ syndromes such as Rett syndrome. 
Table 2 Radiographic variables, mean ( $\pm \mathrm{SD}$ ) for $\mathrm{H} 1$ and $\mathrm{H} 2$ before and after surgery, at follow-up, and average correction

\begin{tabular}{|c|c|c|c|c|c|c|c|c|c|c|c|c|c|}
\hline & \multicolumn{2}{|c|}{$\begin{array}{l}\text { Before surgery } \\
\text { (degrees) } \\
\text { Mean ( } \pm \text { SD) }\end{array}$} & \multicolumn{2}{|c|}{$\begin{array}{l}\text { After surgery } \\
\text { (degrees) } \\
\text { Mean ( } \pm \text { SD) }\end{array}$} & \multicolumn{2}{|c|}{$\begin{array}{l}\text { After surgery } \\
\text { Mean } \\
\text { correction } \%\end{array}$} & \multirow[t]{2}{*}{$P$-value ${ }^{*}$} & \multicolumn{2}{|c|}{$\begin{array}{l}\text { Follow-up } \\
\text { (degrees) } \\
\text { Mean }( \pm \text { SD) }\end{array}$} & \multicolumn{2}{|c|}{$\begin{array}{l}\text { Follow-up } \\
\text { Mean } \\
\text { correction \% }\end{array}$} & \multirow[t]{2}{*}{$\boldsymbol{P}$-value ${ }^{*}$} & \multirow[t]{2}{*}{$\begin{array}{l}\text { Loss of } \\
\text { correction } \\
\text { in degrees } \\
\end{array}$} \\
\hline & $\mathrm{Hl}$ & $\mathrm{H} 2$ & $\mathrm{H} 1$ & $\mathrm{H} 2$ & $\mathrm{H} 1$ & $\mathrm{H} 2$ & & $\mathrm{Hl}$ & $\mathrm{H} 2$ & $\mathrm{Hl}$ & $\mathrm{H} 2$ & & \\
\hline Cobb & $60( \pm 32)$ & $58( \pm 26)$ & $20( \pm 19)$ & $30( \pm 20)$ & 66 & 50 & $<.001$ & $23( \pm 21)$ & $30( \pm 20)$ & 59 & 47 & .01 & 2.1 \\
\hline Rotation & $28( \pm 22)$ & $25( \pm 17)$ & $13( \pm 13)$ & $15( \pm 12)$ & 48 & 33 & .01 & $12( \pm 16)$ & $13( \pm 12)$ & 49 & 37 & .04 & 0.2 \\
\hline $\begin{array}{l}\text { Thoracic } \\
\text { kyphosis }\end{array}$ & $22( \pm 38)$ & $36( \pm 21)$ & $26( \pm 18)$ & $31( \pm 13)$ & 64 & 62 & .98 & $27( \pm 17)$ & $32( \pm 15)$ & 61 & 38 & .39 & 1.1 \\
\hline $\begin{array}{l}\text { Lumbar } \\
\text { lordosis }\end{array}$ & $19( \pm 53)$ & $35( \pm 30)$ & $35( \pm 19)$ & $38( \pm 16)$ & 58 & 60 & .71 & $32( \pm 18)$ & $38( \pm 17)$ & 66 & 74 & .84 & 0.1 \\
\hline $\begin{array}{l}\text { Pelvic } \\
\text { obliquity }\end{array}$ & $16( \pm 15)$ & $7( \pm 10)$ & $3( \pm 7)$ & $3( \pm 4)$ & 58 & 29 & .003 & $3( \pm 8)$ & $3( \pm 5)$ & 51 & 28 & .01 & 0.2 \\
\hline & \multicolumn{13}{|c|}{ Total for study group } \\
\hline Cobb & $59 \pm 29$ & & $25 \pm 20$ & & 57 & & & $27 \pm 21$ & & 53 & & & 2 \\
\hline Rotation & $26 \pm 19$ & & $14 \pm 13$ & & 40 & & & $13 \pm 13$ & & 43 & & & 0.3 \\
\hline $\begin{array}{l}\text { Thoracic } \\
\text { kyphosis }\end{array}$ & $29 \pm 31$ & & $29 \pm 16$ & & 63 & & & $30 \pm 16$ & & 49 & & & 1 \\
\hline $\begin{array}{l}\text { Lumbar } \\
\text { lordosis }\end{array}$ & $27 \pm 43$ & & $36 \pm 17$ & & 59 & & & $35 \pm 17$ & & 70 & & & 0.1 \\
\hline $\begin{array}{l}\text { Pelvic } \\
\text { obliquity }\end{array}$ & $11 \pm 13$ & & $3 \pm 6$ & & 42 & & & $3 \pm 6$ & & 39 & & & 0.1 \\
\hline
\end{tabular}

${ }^{*} P$-value of the difference in correction percentage between $\mathrm{H} 1$ and $\mathrm{H} 2$ adjusted for baseline differences between groups using multiple logistic regression.

Table 3 Length of surgery, intensive care unit (ICU) and hospital stay, and relative bleeding for total study group and according to departments

\begin{tabular}{lllllll}
\hline Operative outcome, mean & $\begin{array}{l}\text { Total study group } \\
\mathbf{n = 1 3 6}\end{array}$ & $\begin{array}{l}\mathbf{H 1} \\
\mathbf{n = 6 5}\end{array}$ & $\begin{array}{l}\mathbf{H 2} \\
\mathbf{n = 7 1}\end{array}$ & Difference & $\begin{array}{l}\mathbf{9 5 \%} \text { Confidence interval } \\
\text { of the difference }\end{array}$ & \multicolumn{1}{c}{$\boldsymbol{P}$-value* } \\
\hline Surgery time, $\boldsymbol{\text { min }}$ & 535 & 498 & 572 & 74 & $-145.8,-1.6$ & .01 \\
\hline ICU stay, days & 1.6 & 1.7 & 1.5 & 0.2 & $-0.15,0.7$ & .39 \\
\hline Hospital stay, days & 11.6 & 12.5 & 10.8 & 1.7 & $-1,4.4$ & .25 \\
\hline Relative bleeding, \% & 73 & 80.3 & 66 & 14.3 & $-2.2,30.8$ & .13 \\
\hline Correction of Cobb angle, \% & 57.9 & 66.5 & 50.4 & 16.1 & $8.1,23.7$ & $<.001$ \\
\hline
\end{tabular}

${ }^{*} P$-value of the difference between $\mathrm{H} 1$ and $\mathrm{H} 2$ adjusted for baseline differences between groups using multiple logistic regression. 
Table 4 Complications for whole study group and according to departments

\begin{tabular}{|c|c|c|c|}
\hline Complications & $\begin{array}{l}H 1 \\
n=65\end{array}$ & $\begin{array}{l}H 2 \\
n=71\end{array}$ & $P$-value* \\
\hline & $\mathrm{n}(\%)$ & $\mathrm{n}(\%)$ & \\
\hline \multicolumn{4}{|l|}{ Minor complications } \\
\hline Urinary tract infection & $3(4.7)$ & $3(4.2)$ & \\
\hline Allergic reaction & $1(1.6)$ & $1(1.4)$ & \\
\hline Headache & $0(0)$ & $1(1.4)$ & \\
\hline Superficial wound infection & $0(0)$ & $3(4.2)$ & \\
\hline Pneumothorax & $0(0)$ & $1(1.4)$ & \\
\hline Laryngospasm & $0(0)$ & $1(1.4)$ & \\
\hline Lung atalectasis & $1(1.6)$ & $1(1.4)$ & \\
\hline Anesthesia (other) & $0(0)$ & $1(1.4)$ & \\
\hline Profuse vomiting & $0(0)$ & $1(1.4)$ & \\
\hline Pressure sores & $2(3.1)$ & $2(2.8)$ & \\
\hline Prominent iliac crest screw, without need for intervention & $2(3.1)$ & $0(0)$ & \\
\hline Keloid scarring & $1(1.6)$ & $1(1.4)$ & \\
\hline Pleuritis & $0(0)$ & $1(1.4)$ & \\
\hline Aspiration & $1(1.6)$ & $0(0)$ & \\
\hline Total minor complications (20.6\%) & $11(16.9)$ & $17(23.6)$ & .38 \\
\hline \multicolumn{4}{|l|}{ Major complications } \\
\hline Mortality & $0(0)$ & $0(0)$ & \\
\hline Neurologic deterioration & $0(0)$ & $0(0)$ & \\
\hline Decrease in functional capacity & $0(0)$ & $0(0)$ & \\
\hline \multicolumn{4}{|l|}{ Hospital-related major complications† } \\
\hline Part of drain left in pleural cavity during removal & $0(0)$ & $1(1.4)$ & \\
\hline Deep infection & $2(3.1)$ & $5(6.9)$ & \\
\hline Pneumonia & $1(1.6)$ & $3(4.2)$ & \\
\hline CVK-induced septicemia & $0(0)$ & $1(1.4)$ & \\
\hline Total & $3(4.7)$ & $10(13.9)$ & .06 \\
\hline \multicolumn{4}{|c|}{ Surgical procedure or implant-related major complications } \\
\hline Prominent iliac crest screw, removal operation & $4(6.3)$ & $1(1.4)$ & \\
\hline Other implant-related problems, removal operation & $1(1.6)$ & $0(0)$ & \\
\hline Pseudarthrosis & $0(0)$ & $1(1.4)$ & \\
\hline Progression outside fusion & $1(1.6)$ & $0(0)$ & \\
\hline Total & $6(9.4)$ & $2(2.8)$ & .17 \\
\hline Total major complications (15.4\%) & $9(14.1)$ & $12(16.7)$ & .48 \\
\hline All infections( within major and minor complications) & $6(9.4)$ & $16(22.2)$ & .04 \\
\hline
\end{tabular}

* P-value calculated adjusted for the baseline data differences (gender, diagnosis of MMC, wheelchair bound, and neurosurgery performed).

$\dagger$ Events not related to surgical procedures or implants. 


\section{DISCUSSION}

\section{Short synthesis:}

- High-risk spine surgery can be performed safely and with good outcome.

- The H1 and H2 department comparisons showed differences in complication occurrence, surgery time, and correction percentage. $\mathrm{Hl}$ had better outcomes despite longer follow-up time and tendency to have more involved patients.

\section{Strengths:}

- Data was prospectively captured.

- Treatment program was consequent.

- Only one senior orthopaedic and neurosurgeon.

- All consequently included cases were followed up for 2 or more years.

\section{Limitations:}

- Data from Hl was included during 8 years, whereas H2 during 5 years.

- Possible differences at baseline may have confounded results.

\section{Short synthesis from findings from other studies:}

- The overall complication rate in the current study is low compared with earlier literature [1, 3, 4-6].

- Risk for complications have been studied from diagnosis/disease perspective, but the possible impact of occupational organization is also worth analyzing due to its documented importance in other production fields $[9,10]$.

\section{Clinical relevance and impact:}

- Complex surgery on high-risk patients can be performed with good outcome and be justified. In addition to medical patient parameters, workplace culture and organization may have an impact.

\section{SUMMARY AND CONCLUSION}

- Major spinal deformity surgery on high-risk patients is safe enough to be justified.

- Significant outcome differences were found in favor of a multidisciplinary specialized department.

- Further prospective studies on the impact of workplace culture and organization on the surgical outcome in high-risk surgery is indicated. 


\section{REFERENCES}

1. Bowman RM, McLone DG, Grant JA, et al (2001) Spina bifida outcome: a 25-year prospective. Pediatr Neurosurg; 34(3):114-120.

2. Banit DM, Iwinski HJ Jr, Talwalkar V, et al (2001) Posterior spinal fusion in paralytic scoliosis and myelomeningocele. I Pediatr Orthop; 21(1):117-125.

3. Barsdorf AI, Sproule DM, Kaufmann $\mathbf{P}$ (2010) Scoliosis surgery in children with neuromuscular disease: findings from the US National Inpatient Sample, 1997 to 2003. Arch Neurol; 67(2):231-235.

4. Geiger F, Parsch D, Carstens C (1999) Complications of scoliosis surgery in children with myelomeningocele. Eur Spine J; 8(1):22-26.

5. Modi HN, Suh SW, Yang JH, et al (2009) Surgical complications in neuromuscular scoliosis operated with posterior-only approach using pedicle screw fixation. Scoliosis; 4:11.

6. Mohamad F, Parent S, Pawelek J, et al (2007) Perioperative complications after surgical correction in neuromuscular scoliosis. $J$ Pediatr Orthop; 27(4):392-397.

7. Tsirikos Al, Lipton G, Chang WN, et al (2008) Surgical correction of scoliosis in pediatric patients with cerebral palsy using the unit rod instrumentation. Spine; 33(10):1133-1140.

8. Larsson A, Uusijärvi J, Lind F, et al (2010) Hyperbaric Oxygen (HBO) in the treatment of postoperative infections in paediatric patients with neuromuscular spinal deformity. Eur Spine J; in press.

9. Anderson JJ, Mokracek M, Lindy CN (2009) A nursing quality program driven by evidence-based practice. Nurs Clin North Am; 44(1):83-91.

10. Schell E (2008) Work environment and health determinants. Longitudinal, controlled intervention and cross-sectional studies in public-service broadcasting companies. [Ph.D dissertation]. Karolinska Institutet, Stockholm, Sweden.

\section{EDITORIAL STAFF PERSPECTIVE}

This study has very good data with minimal 2-year follow-up on a difficult mixture of pediatric deformity patients. The strength of the study is the number of patients and follow-up with detailed multifocal observation points including radiographic and clinical parameters.

The consideration of the influence of a hospital environment on patient safety (ie, complications), and patient outcomes (ie, function and general well-being) is a fascinating one, and one that may engender substantial controversy. In this unique study the authors were able to exclude patient, surgeon, and surgical technique factors, which usually represent the majority of variables assessed in clinical research. Instead, they seemingly had a very similar population treated in two hospitals by the same two surgeons-the selection of hospital allocation apparently being made at a higher level-and we are to assume independent - administrative entity.

Our reviewers universally congratulated the authors on coming up with the idea for this research and compiling a thoughtful and detailed array of data points supporting substantial differences in complication rates between the two different hospital systems. Of course, our reviewers were interested in further clinical details to validate the comparisons of patient disease severity between hospitals. For instance, the authors had used a general functional categorization of 'ambulators,' 'ambulators with concordant neurologic disease,' 'ambulators using supportive devices for locomotion' and 'wheelchair bound' status. While such broad categorizations do not offer a quantifiable neurologic status representation, it appears to serve the purposes of the study population well. In the end we are to assume that the absence of reported neurologic deteriorations implied no changes within these general operational functional categorizations specific to this study population.

Another concern was that of perioperative nutritional status: were the two study populations of comparable preoperative nutritional status, or did one group receive more advanced nutritional assessment / support than the other?

As to the differences of the practice models and possible causes for the differences in wound complications, pulmonary related issues, sepsis and anesthetic issues, the authors provided some very general thoughts without being able to pinpoint specific systems related factors as causes. We do encourage our EBSJ readers to look at the web appendix, in which the authors go into further details on differences in care delivery. This can be found at www. aospine.org/ebsj.

A final caveat to the study relates to the country of origin: with the high quality surgical care as well as sophisticated supportive staff available in Sweden, reported safety data may not be pertinent elsewhere. Similarly, hospital related differences regarding different 'production units' may not translate well either.

In the end, the main question raised by this study remains a very compelling one: should certain patients with certain diseases preferably be treated in specialized centers rather than the next available facility? If such a selection of care facility is made-should this affect patients with complex conditions (such as presented in this article by Murans) only, or should it extend to patients with routine and straightforward conditions as well? And finally - who should choose - the patient, a referring provider or a higher level administrative capacity? 